Research Article

\title{
Influence of Sowing Time on Cabbage Aphid (Brevicoryne brassicae L.) (Homoptera; Aphididae) Population in Different Brassica Species under Field Condition
}

\author{
Shaista Shaf* and Amjad Farooq \\ Department of Pure and Applied Biology, Bahauddin Zakariya University Multan, Punjab, Pakistan.
}

\begin{abstract}
The experiment was carried out to highlight the outcome of planting date on the emergence of aphids in different species of brassica at Agricultural College of Bahauddin Zakariya University Multan, Punjab (Pakistan) during 2014-2015 and 2015-2016. Four brassica species (B. carinata, B. rapa, B. napus and B. juncea) were seeded from October to November at different dates (Octo 20, Nov 05, Nov 20) in RCBD design (Randomized Complete Block Design) with standard cultivation procedures to detect the effect of sowing date on Brevicoryne brassicae population. Data were noted weekly and evaluated statistically. The ANOVA revealed highly significant effects of drill dates and species on Brevicoryne brassicae populations, while brassica species $\times$ sowing date interaction was also highly significant. Early sown crops bore fewer aphid populations in contrast to mid and late sown crops. Therefore, it may be concluded that mid-October can be recommended for the farming of brassica crops.

Received | August 14, 2020; Accepted | May 11, 2021; Published | July 12, 2021

*Correspondence | Shaista Shafi, Department of Pure and Applied Biology, Bahauddin Zakariya University Multan, Punjab, Pakistan; Email: shaasbzu@yahoo.com

Citation | Shafi, S. and A. Farooq. 2021. Influence of sowing time on cabbage aphid (Brevicoryne brassicae L.) (Homoptera; Aphididae) population in different brassica species under field condition. Sarhad Journal of Agriculture, 37(3): 993-998.

DOI | https://dx.doi.org/10.17582/journal.sja/2021/37.3.993.998

Keywords | Aphid infestation, Aphid population, Brassica genotypes, Environmental condition, Sowing date
\end{abstract}

\section{Introduction}

T he production of edible oil is less than the domestic use of people. Pakistan used 40 billion rupees to import edible oil every year. Mustard and rapeseed are cultivated on 327.3 thousand hectare area in Pakistan (Annon, 2000). The production and yield of the edible oil can be improved by growing cultivars of brassica through production technology instead of growing indigenous rapeseed and mustard crops. The important factor to increase the production of oilseed crops is planting date particularly in those regions where, the degree of heat, length of the day, fall of rain, and moisture/evaporation are changed in the whole areas (Jhonson et al., 1995).
Tanveer and Karam (1998) reported the effect of seeding time on the yield production of brassica. Yield production of brassica had severely affected due to late sowing, because of many cropping systems brassica cannot be cultivated at the proper time particularly after potato, cotton rice, and other crops of the winter season (Ansari et al., 1990). The presence of insects on crops depend upon the climatic conditions that gradually changes with the movement of the yearly calendar. According to various studies, planting schedule played a dynamic role in the presence of insect pests in crops (Razaq et al.,2011). Planting date is seriously concerned for a crop since it involves the favorable season and time for pest attack (Mendham et al., 2009). 
Commonly, some pest attacks under certain environmental conditions that change time by time and connected to dates. Seasonal changes move by half of the month and sometimes they are predictable while occasionally they become uncertain. Impact of the sowing date becomes evident on infestation of pests (Yousaf et al., 2002).

Crop production and infestation of pests should not be correlated positively instead a reverse relationship is desirable. The crop should not be seeded when the chances of infestation are maximum i.e. environmental conditions are favorable for rapid propagation of insects. Certain dates are more appropriate for insects and pose substantial loads while other cultivation time is not appropriate for insects to attack (Gull and Ahmad, 2007). Seed yield is a difficult charm that can be determined by numerous apparatuses reflecting positive or negative effects upon trait. Influence of many components in demand to give extra attention to those having the highest influence on seed yield (Saljoqi et al., 2009).

Rapeseed and mustard seed crops are cultured/ sown from the last week of September to fifteen October. These crops can be cultivated singly or by intercropping. The performance of late sown crops has been badly affected due to change in abiotic and biotic factors (Singh and Sinhal, 2011). The macroclimatic condition also affects the aphid disturbance and movement (Bisnoi, 2007).

The purpose of this study was to analyze the consequence of sowing date on infestation of pests and to investigate the quantity of $B$. brassicae aphids attacking the brassica species in the southern belt of Punjab, Pakistan.

\section{Materials and Methods}

The tests were conducted at the Agricultural College of B.Z.U, Multan, Pakistan, during the Rabi season of 2015 and 2016. Four Brassica species representing Brassica napus, Brassica rapa, B. carinata and $B$. juncea collected from NARC (National Agricultural Research Council) Islamabad. Brassica varieties were sown along with the different date of sowing including early, mid, and late season in Randomized Complete Block Design (RCBD) with three replication of different dates including Octo 20 (First sowing), Nov 5 (Second sowing), and Nov 20 (Third sowing) were selected for raising the crops. Seeds of brassica were sown in a micro-plot $(4 \times 2 \mathrm{~m})$ with spacing of $15 \mathrm{~cm}$ and $45 \mathrm{~cm}$ plant to plant and row to row, respectively. For good germination, ploughing of the experimental field was done and the recommended level of fertilizers $\left[\mathrm{N}\left(60 \mathrm{Kg}+\mathrm{P}_{2} \mathrm{O}_{5}(40 \mathrm{Kg})\right.\right.$ and $\mathrm{K}_{2} \mathrm{O}(40 \mathrm{Kg})$ were mixed in the soil. Thinning was carried out after 20 days of emergence and crop was harvested at maturity. Population of aphid (B. brassicae) was recorded from original arrival to final withdrawal of the annoyance by removing aphid from $10 \mathrm{~cm}$ top portion of the mortal shoot with the help of acamel hair brush on a white paper sheet. Then the figures of aphid were calculated. The mean minimum and maximum temperature varied in between 11.3 to $23.1^{\circ} \mathrm{C}$ and 10.7 to $24.3^{\circ} \mathrm{C}$, respectively and mean rainfall, 96.4 $\mathrm{mm}$ and $22.6 \mathrm{~mm}$ rains were recorded during whole growth period. The data were collected weekly and subjected to analysis of variance (ANOVA) by using STATICS 8.1 and means value were separated by calculating least significant difference test at $\mathrm{P}=0.05$. This method has also been employed in sampling $L$. erysimi in India on Brassica juncea (Ameer et al., 2009; Ali and Rizvi, 2012). This method is effective, saves, labour, resources, power and time.

\section{Results and Discussion}

Analysis of variance identified significant differences between all Brassica species infected by Bravicoryne brassica during 2015and 2016. Similarly, the planting dates were also create significantly different for $B$. brassicae population count during both years, while on the other hand the interaction among species and sowing date for B. brassicae was found highly significantly different in both years (Table 1 ).

Table 1: Analysis of variance table for Brevicoryne brassicae population count during 2015 and 2016.

$\begin{array}{lll} & \mathbf{2 0 1 5} & \mathbf{2 0 1 6} \\ \text { Species } & 0.0000 & 0.0025 \\ \text { Sowing Time } & 0.0000 & 0.0141 \\ \text { Species } \times \text { Sowing Time } & 0.0000 & 0.0000\end{array}$

$\mathrm{P} \leq 0.05$ Significant, $\mathrm{P} \leq 0.01$ Highly significant

$P$ value is the probability value, if value of $P$ is less than 0.05 the results are significant. These values are calculated through analysis of variance (ANOVA).

As presented in Figure 1, all through 2015among all brassica species $B$. juncea exposed minimum growth of $B$. brassicae, while $B$. carinata showed its maximum 
growth than rest of species. B. napus whereas $B$. rapa exhibited the intermediate values of $B$. brassica population, however, B. rapa was least infected by aphid.

a (2015)

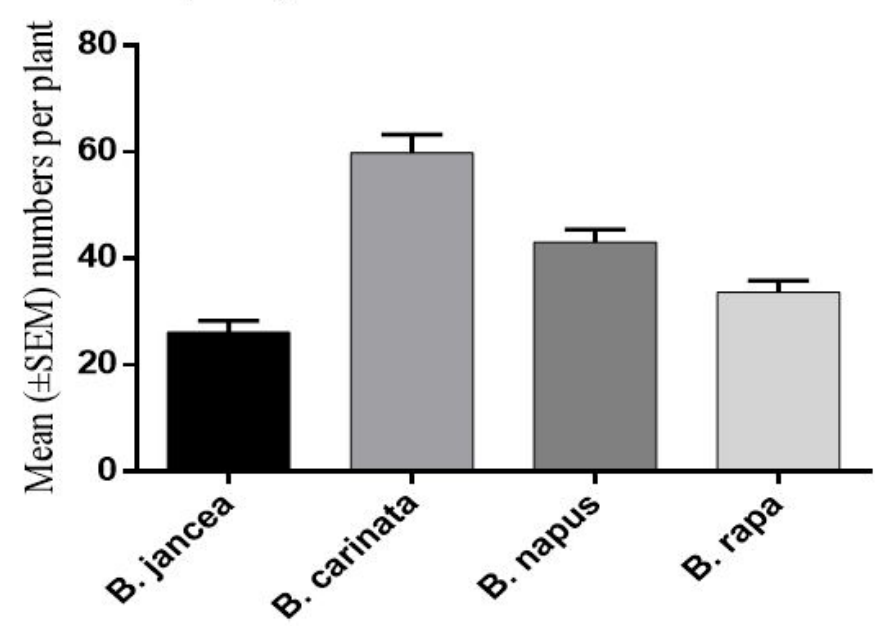

Figure 1: Mean Brevicoryne brassicae population on different species of brassica during 2015.

During 2016 B. brassicae also significantly influenced all observed brassica species. Results presented in Figure 2, among all brassica species B. Carinata exposed highly infestation by $B$. brassica and found sensitive as compared to rest of brassica species. $B$. juncea was little infected in contrast to the result of 2015. However, B. napus and B. rapa did not show significant variation among themselves (Figure 2).

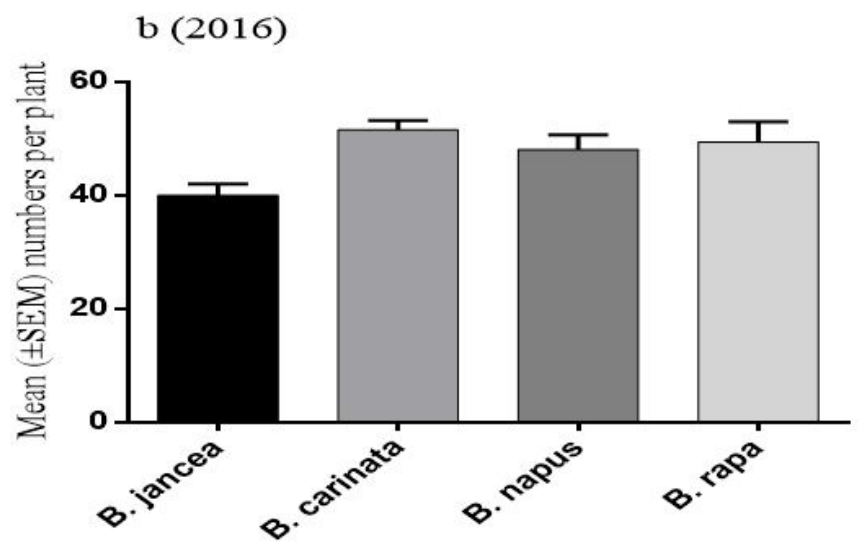

Figure 2: Mean Brevicoryne brassicae population on different species of brassica during 2016.

ANOVA result of 2015 (Figure 3) presented maximum average population of Brevicoryne brassicae at early sowing date $(20 \mathrm{Oct})$ but it appears to decline at second sowing date while late sown crop (20 Nov) exposed extreme number of $B$. brassica population. Although more information could not be found about studying of more than two brassica species at a time, according to researched literature, results are in line with the result of Dharavath et al. (2017) and Patel et al., (2004). They determined the significant effect of sowing date on B. juncea.

a (2015)

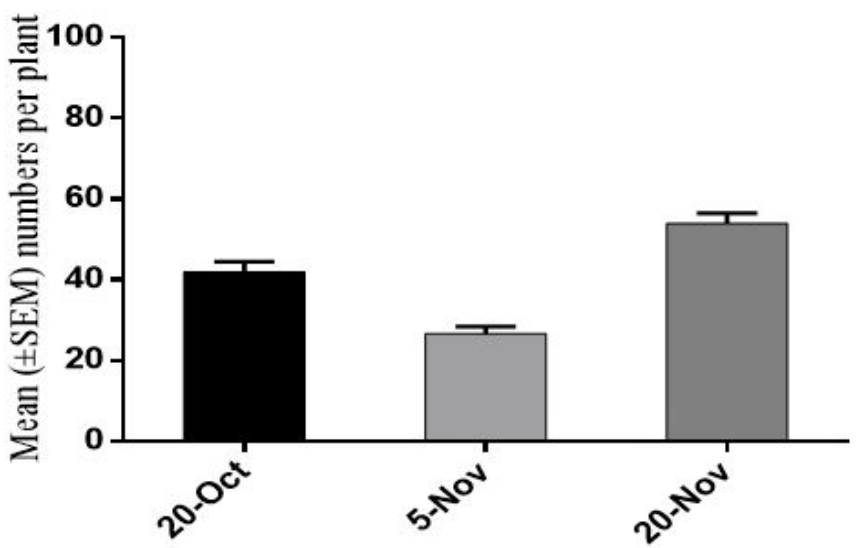

Figure 3: Means count of B. brassicae population on different dates during 2015.

According to ANOVA (Table 1 ), at early sowing dates (20 Oct) the mean population of B. brassicae recorded highest as compared to the second sowing date (5Nov) which increased gradually with the change of time period and recorded maximum at late sowing dates (20 Nov)

\section{b (2016)}

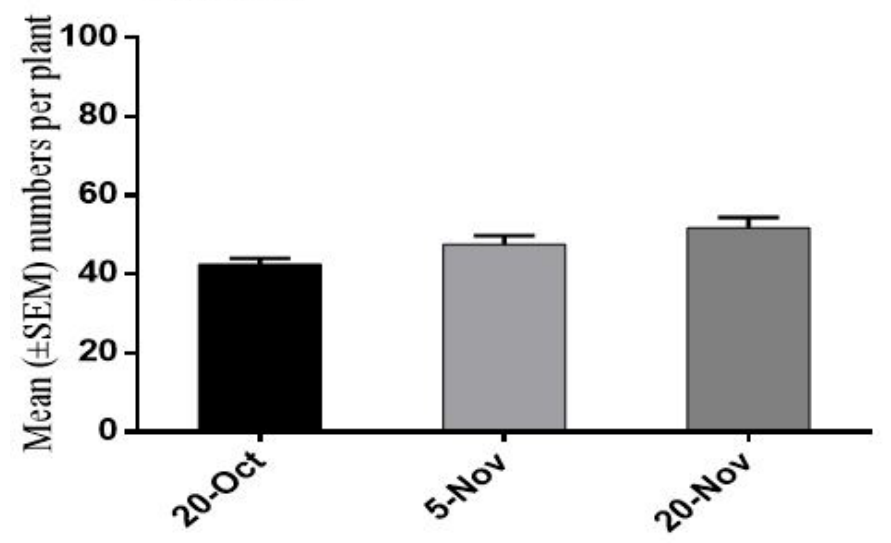

Figure 4: Means count of $B$. brassicae population on different dates during 2016.

Contradiction appeared between the results of 2015 and 2016. Some climatic conditions might have influenced the experimental conditions. The brassica species not necessarily influenced the number of pests attacking the crops but some environmental conditions (temperature, rainfall, sunshine relative humidity) also flourished the pest population.

But the result of 2016 also in line with the result of 
Razaq et al.(2012). These findings are also concurrence with the findings of other researchers (Afroz et al., 2011; Siddiqui et al., 2009; Saljoqi et al., 2009). Such findings have also been presented by Rameeh (2012) who reported the significant influence of planting dates. Shah and Rahman (2009) have reported the influence of planting date on plant traits. Early sown crops bore fewer aphid populations as contrast to mid and late sown crops. As late sowing crops offers a better chance of the growth stage of plants having tender shoots and ultimately mustard aphids colonize the crop at an earlier growth stage. The accessibility of such favorable situations affects the prolonged existence of aphid at Brassica crops (Rehman et al., 2009). Genetically some brassica species are more vulnerable and susceptible to aphid's population causes the great loss of yield, while some species of brassica show resistance and natural enemies appear too late (Dharavath et al., 2017).

Interaction among brassica species and sowing date (Figure 5) B. brassicae establish highly significant effect in both years of research. At early sowing (20 Oct) B. carinata exhibited supreme aphid population (11.22a, 8.12a) and slightest population was observed at B. juncea and B. rapa $(1.97 \mathrm{c}, 3.595)$, respectively, while late sowing crop (20 Nov) have utmost $B$. brassicae population on B. carinata $(9.79 \mathrm{bc}, 6.38)$ and least $B$. brassicae population recorded on $B$. juncea (6.527d, 5.04), respectively. According to result $B$. juncea specie is less susceptible than rest of observed brassica species while $B$. carinata is more susceptible than other examined brassica species.

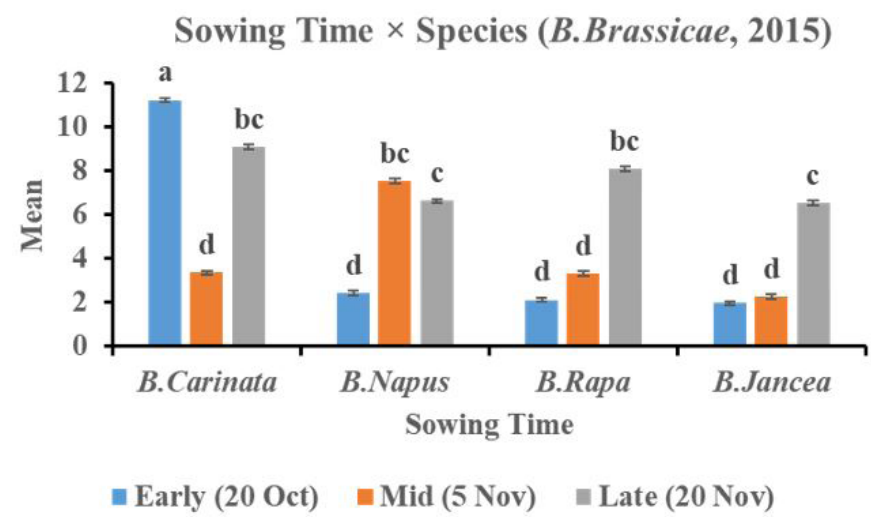

Figure 5: Interaction table of sowing date and various brassica species during 2015.

Interaction result among sowing date and brassica species (Figure 6) of 2016 shows at early sowing date (20 Oct) B. carinata have maximum (11.22a) and $B$. rapa exhibit least (3.595d) B. brassicae population, while during late sown period (20 Nov) B. carinata and B. juncea have highest (8.533a) and lowest aphid population $(5.047 \mathrm{~cd})$ respectively.

Sowing Time $\times$ Species (B.Brassicae 2016)

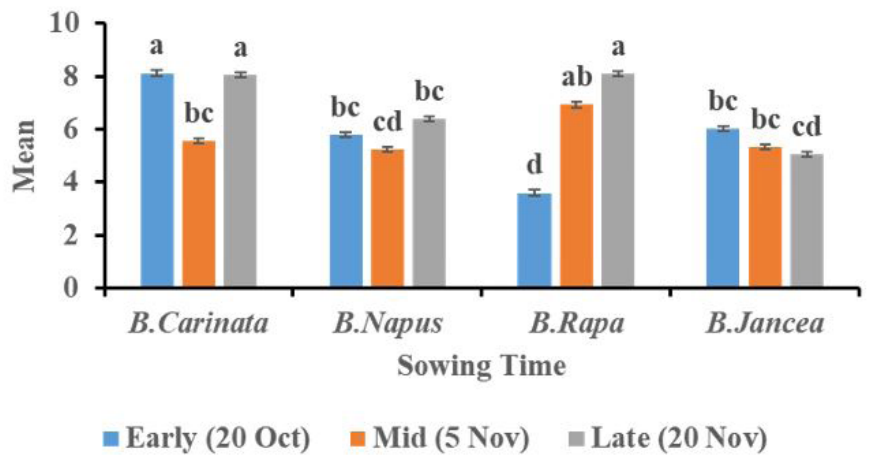

Figure 6: Interaction table of sowing date and various brassica species during 2016.

According to the result of 2016 B. carinata was examined more susceptible at early and late sown period. Whereas B. rapa was found less susceptible at early sown crops which increases gradually in hypernolic fashion, ultimately spoiled the crops. Among all species of aphids attack brassica crops on various dates, mean population of cabbage aphid (B. brassicae $\mathrm{L}$ ) was less in number, appeared late and finally damaged the plants.

While B. napus and B. juncea species showed a midway ratio of $B$. brassicae population. These findings concurrence with studies by Din et al. (2007) reported the effect of sowing date on the growth of plants and found significant effects. Such reports have been presented by Gull and Ahmad (2007) matching with findings of other studies. A study by (Karam, 1998) presented the effect of sowing dates on various plant parameters. Such a study has been conducted by Ansari et al. (1990). Bhuiyani et al. (2008) also examined the effect of planting times and reported significant results supporting the present findings. Yousaf et al. (2002) highlighted the effect of different sowing date on plant traits and found significant effects. Genetically some brassica species are more vulnerable and susceptible to aphid's population which causes a great loss of yield, while some genotypes of brassica show resistance and natural enemies appear too late (Dharavath et al., 2017).

\section{Conclusions and Recommendations}

The impact of sowing date on B. brassicae population on various brassica species is evident. The environmental 
conditions also support in flourishing the pest population. It was recorded that early sown crops bore fewer aphid populations as compared to mid and late sown crops during both years of study. From this research, it may be concluded that mid-October is a favorable time for planting of brassica crops. Therefore, farmers can sow any of the species among B. juncea, B. napus and B. carrinata but B. napus will be the better choice as this species is economically more important

\section{Acknowledgments}

I acknowledge with gratitude the department of National Agricultural Research Centre (NARC), Islamabad for providing the seeds of brassica varities. Special thanks to the company of Dr. Walli (Research Scientist) and all the coworkers (PARC Multan). They guided and facilitated us during the whole period of data collection. I would like to express our special gratitude to Dr. Farhan Shah (Department of Entomology) for analysis and helping in the major revision of the manuscript.

\section{Novelty Statement}

This study discovers those brassica species, which are not implemented till under field condition.

\section{Author's Contribution}

Shaista Shafi: Conception and design of work, data collection, analysis and interpreting the data, wrote article, critical revision article.

Amjad Farooq: Conception and planned researchwok, guidance in written work, support and help in analysis

\section{Conflict of interest}

The authors have declared no conflict of interest.

\section{References}

Afroz, M.M., M.A.R. Sarkar., M.S.U. Bhuiya and A.K. Roy. 2011. Effect of sowing date and seed rate on yield performance of two mustard varieties. J. Bangladesh Agric. Univ., 9(1): 5-8. https://doi.org/10.3329/jbau.v9i1.8737

Ali, A. and P.Q. Rizvi. 2012. Influence of abiotic and biotic factors on the population dynamics of mustard aphid, Lipaphiserysimi (Kalt.) On
Indian mustard Brassica juncea with respect to sowing dates. Acad. J. Plant Sci., 5(4): 123-127. https://www.idosi.org/ajps/5(4)12/4.pdf

Amer, M., M. Aslam, M. Razaq and M. Afzal. 2009. Lack of plant resistance against aphids, as indicated by their seasonal abundance in canola, Brassica napus (L.) in Southern Punjab, Pakistan. Pak. J. Bot., 41(3): 1043-1051. http://www. pakbs.org/pjbot/PDFs/41(3)/PJB41(3)1043. pdf

Anonymous. 2000. Economic Survey of Pakistan. Ministry of Food, Agriculture and Livestock, Islamabad, Pakistan. pp. 34-36.

Ansari, A.H., S.M. Qayyum, A.A. Mirza and N.A. Chaudhry. 1990. Effect of different sowing dates on growth and yield of three varieties of mustard. Pak. J. Agric. Res., 11(4): 234-238.

Begna, S.H. and S.V. Angadi. 2016. Effects of planting date on winter canola growth and yield in the southwestern U.S. Am. J. Plant Sci.,7(01): 201-217. https://doi.org/10.4236/ ajps.2016.71021

Bhuiyan, M.S., M.R.I. Mondol, M.A. Rahaman, M.S. Alam and A.H.M.A. Faisal. 2008. Yield and yield attributes of rapeseed as influenced by date of planting. Int. J. Sustain. Crop Prod., 3(3): 25-29.

Bisnoi, O.P. 2007. Principles of agricultural meteorology. PHI Learning Pvt Ltd., New Delhi. http:/www.aau.in/sites/default/ files/Agricultural\%20Meterology.pdf

Dharavath, N., B. Mehera, S. Nath, S.S. Patra and S. Rout. 2017. Effect of different sowing dates and application of pesticides on growth and yield of mustard crop (Brassica juncea). Int. J. Pure App. Biosci., 5(1): 178-187. https://doi. org/10.18782/2320-7051.2434

Din, M., M. Qasim, N. Elahi and Faridullah. 2007. Response of different sowing dates on the growth and yield of cauliflower. Sarhad J. Agric., 23(2): 289-291. http://www.aup.edu. $\mathrm{pk} / \mathrm{sj}$ _pdf/response\%20of\%20different $\% 20$ sowing $\% 20$ dates $\% 20$ on\%20the.pdf

Gul, H. and R. Ahmad. 2007. Effect of different sowing dates on the Vegetative and reproductive growth of Canola (Brassica napus) Cultivars Under different salinity levels. Pak. J. Bot., 39(4): 1161-1172.

Johnson, B.L., K.R. Schneiter, A.A.B.K. Hanson and B.G. Schatz. 1992. Influence of planting date on canola and crambe production. J. Prod. 
Agric., 49(4): 23-26. https://library.ndsu.edu/ ir/handle/10365/27804

Karam, I. 1998. Effect of Planting time and row spacing on growth, yield and oil content of Canola (Brassica napus). M.Sc. thesis, Dept. Agron. Univ. Agric. Faisalabad, Pakistan.

Mendham, N.J., P.A. Shipway and P.K. Scott. 2009. The effects of delayed sowing and weather on growth, development and yield of winter oilseed rape (Brassica napus). J. Agric. Sci., 96(2): 389-416.

Patel, S.R., A. Awasthi and R.K.S. Tomar. 2004. Assessment of yield losses in mustard (Brassicajuncea L.) due to mustard aphids (Lipaphiserysimi Kalt.) under different thermal environment in eastern Central India. Appl. Ecol. Environ. Res., 2(1): 1-15. https://doi. org/10.15666/aeer/02001015

Rahman, M.H., M.R. Hasan, M. Ahmad, and M.A. Haque. 2009. Aphid incidence and its correlation with different environmental factors. J. Bangladesh Agril. Univ. 7(1): 15-18.

Rameeh, V. 2012. Evaluation of the Planting dates effects on yield and yield associated traits in rapeseed advanced lines. Int. J. Agric. Inno. Res., 1(1): 2319-1473.

Razaq, M., S. Maqsood, M. Aslam, S.A. Ismail and M. Afzal. 2012. Effect of plant spacing on aphid population, yield components and oil contents of late sown canola, Brassica napus L. (Brassicaceae). Pakistan J. Zool., 44(4): 991995.

Razaq, M., R.A. Mehmood, M. Aslam, M. Ismail,
M. Afzal and S.A. Shad. 2011. Losses in yield and yield components caused by Aphids to late sown Brassica napus Brassica Juncea and Brassica carinata a. Braun at Multan, Punjab (Pakistan). Pak. J. Bot., 43(1): 319-324.

Saljoqi, A.U.R., T. Khan, S. Rehman, Wasiullah and M. Liaqatullah. 2009. Effects of two potential pest management components, Time of sowing and selective use of chemicals for the management of aphids (Lipaphiserysimi kalt) in canola crop. Sarhad J. Agric., 25(4): 563-571.

Shah, S.A. and K. Rahman. 2009. Yield and growth response of rapeseed (Brassica napus) mutants to different seeding rates and sowing dates. Pak. J. Bot., 41(6): 2711-2716.

Siddiqui, S.S., M. Naeem and N.A. Abbasi. 2009. Effect of planting dates on aphids and their natural enemies in cauliflower varieties. Pak. J. Bot., 41(6): 3253-3259.

Singh, P. and V.K. Sinhal. 2011. Effect of Aphid infestation on the Biochemical Constituents of mustard (Brassica juncea) plant. J. Phytol., 3(8): 28-33. https://updatepublishing.com/journal/ index.php/jp/article/view/2308

Tanveer, S., N.I. Kahan and F. Saeed. 1998. Effect of different sowing methods and sowing dates on the grain yield of canola sarson. J. Agric. Res., 36: 145-150.

Yousaf, M., A. Ahmad, M. Jahangir and T. Naseeb. 2002. Effect of different sowing dates on the growth and yield of canola (Sarson) varieties. Asian J. Plant Sci., 1(6): 634-635. https://doi. org/10.3923/ajps.2002.634.635 